\title{
Stereospecific polymerization of vinyl acetate in fluoroalcohols Synthesis of syndiotactic poly(vinyl alcohol)
}

\author{
By Kazunobu Yamada, $\left.{ }^{*}, * *\right)$ Tamaki NaKano, ${ }^{* * *)}$ and Yoshio OKamoto***),t) \\ (Communicated by Seizo OKamura, M. J. A., March 12, 1998)
}

\begin{abstract}
The free-radical polymerization of vinyl acetate (VAc) was carried out in various alcoholic solvents. Fluoroalcohols with a lower $\mathrm{p} K \mathrm{a}$ and higher bulkiness were effective in enhancing the syndiotactic specificity of the polymerization. The polymerization of VAc in perfluoro-tert-butyl alcohol $\left(\left(\mathrm{CF}_{3}\right)_{3} \mathrm{COH}\right)$ at $-78^{\circ} \mathrm{C}$ led to a dyad syndiotacticity of $72 \%$, which is the highest value reported for the radical polymerization of vinyl esters. Hydrogen-bonding between the acetyl groups of VAc and polymer and the fluoroalcohol molecule may be responsible for the enhancement of the syndiotactic specific propagation.
\end{abstract}

Key words : Poly(vinyl alcohol); radical polymerization; tacticity; vinyl acetate; fluoroalcohol; hydrogenbond.

Introduction. Poly(vinyl alcohol) (PVA) is commercially produced by the radical polymerization of vinyl acetate (VAc) followed by saponification of the obtained polymers. Although free-radical polymerization of VAc generally affords atactic PVA, efforts have been made to synthesize PVA with a higher syndiotacticity. This is because a slight change in tacticity has a significant influence on the physical and chemical properties of PVA, and the synthesis of PVA with a higher syndiotacticity is a key process to improve the properties of the polymer. ${ }^{1)}$

It is known that syndiotactic PVA can be obtained by the radical polymerization of bulky vinyl esters such as vinyl trifluoroacetate, ${ }^{2,3)}$ vinyl pivalate $(\mathrm{VPi}),{ }^{4)-6)}$ vinyl diphenylacetate, ${ }^{7)}$ and vinyl 2,2-bis(trifluoromethyl)propionate ${ }^{8)}$ followed by saponification of the obtained polymers. However, this method is effective only for specific monomers and is not a general method.

In the present work, we investigated the solvent effects on the stereochemistry of VAc polymerization in search of a versatile method of syndiotactic PVA

*) Joint Research Center for Precision Polymerization (JRCPP)Japan Chemical Innovation Institute (JCII), Graduate School of Engineering, Nagoya University, Furo-cho, Chikusa-ku, Nagoya 464-8603, Japan.

**) On leave from R \& D Center, Unitika Ltd., 23 Kozakura, Uji, Kyoto 611-0021, Japan.

***) Department of Applied Chemistry, Graduate School of Engineering, Nagoya University, Furo-cho, Chikusa-ku, Nagoya 464-8603, Japan.

t) Correspondence to: Y. Okamoto. synthesis. Although solvents generally have little effect on the stereochemistry of VAc polymerization, ${ }^{9), 10)}$ the polymerization in phenol has been reported to give poly(VAc) rich in syndiotacticity (dyad $r=56.5 \%$ ). ${ }^{11)}$ This effect has been explained in terms of the hydrogen-bonding between VAc and phenol. However, phenol is also known to retard the polymerization of VAc and to reduce the molecular weight of the resulting polymer ${ }^{12)}$ similar to other aromatic solvents. ${ }^{13)}$ Intrigued by the stereochemical effects of phenol, we carried out the polymerization of VAc in various non-aromatic alcoholic solvents including 1,1,1trifluoroethanol $\left(\mathrm{CF}_{3} \mathrm{CH}_{2} \mathrm{OH}\right)$, 1,1,1,3,3,3-hexafluoro-2methyl-2-propanol $\left(\left(\mathrm{CF}_{3}\right)_{2} \mathrm{C}\left(\mathrm{CH}_{3}\right) \mathrm{OH}\right), 1,1,1,3,3,3$-hexafluoro-2-propanol $\left(\left(\mathrm{CF}_{3}\right)_{2} \mathrm{CHOH}\right)$, and perfluoro-tert-butyl alcohol $\left(\left(\mathrm{CF}_{3}\right)_{3} \mathrm{COH}\right)$, which are expected to form strong hydrogen-bonding with the acetyl groups of the monomer and polymer side chains without retarding the polymerization and reducing the molecular weight of the resulting polymer.

Solvent effects. The polymerization of VAc was carried out in various alcoholic solvents using AIBN under UV light irradiation at $20^{\circ} \mathrm{C}$, and the stereochemistry of the polymerization was investigated (Table I). Neither retardation of the polymerization nor reduction in the molecular weight of the resulting polymer was observed for the polymerization in alcoholic solvents. While the stereochemistry of the polymerization in $\mathrm{CH}_{3} \mathrm{OH}$ was similar to that of the bulk polymerization, the polymerization in other solvents resulted in a higher syndiotacticity compared with the bulk polymerization. Among the solvents, $\left(\mathrm{CF}_{3}\right)_{3} \mathrm{COH}$ 
Table I. Radical polymerization of VAc in various alcohols using AIBN under UV irradiation at $20^{\circ} \mathrm{C}^{a}$

\begin{tabular}{|c|c|c|c|c|c|c|c|c|c|c|}
\hline \multirow{2}{*}{ Run } & \multirow{2}{*}{ Solvent } & \multirow{2}{*}{$\begin{array}{c}\mathrm{p} K \mathrm{a}^{b} \\
\text { of solvent }\end{array}$} & \multirow{2}{*}{$\frac{\text { Conv. }^{c}}{\%}$} & \multirow{2}{*}{$\frac{\text { Yield }^{d}}{\%}$} & \multirow{2}{*}{$M n^{e}$} & \multirow{2}{*}{$M w / M n^{e}$} & \multicolumn{3}{|c|}{ Triad tacticity ${ }^{f}$} & \multirow{2}{*}{$\frac{\text { Dyad syndiotacticity }}{r / \%}$} \\
\hline & & & & & & & $m m$ & $m r$ & $r r$ & \\
\hline 1 & None & - & - & 71 & 55400 & 1.85 & 22.6 & 48.9 & 28.5 & 52.9 \\
\hline 2 & $\mathrm{CH}_{3} \mathrm{OH}$ & 16 & 66 & 58 & 10500 & 1.85 & 22.2 & 49.2 & 28.6 & 53.2 \\
\hline 3 & $\mathrm{CF}_{3} \mathrm{CH}_{2} \mathrm{OH}$ & 12.4 & 72 & 62 & 13100 & 1.91 & 19.8 & 49.9 & 30.3 & 55.2 \\
\hline 4 & $\left(\mathrm{CF}_{3}\right)_{2} \mathrm{C}\left(\mathrm{CH}_{3}\right) \mathrm{OH}$ & 9.6 & 75 & 64 & 18800 & 2.67 & 17.9 & 50.0 & 32.1 & 57.1 \\
\hline 5 & $\left(\mathrm{CF}_{3}\right)_{2} \mathrm{CHOH}$ & 9.3 & 76 & 81 & 16600 & 2.03 & 18.6 & 49.1 & 32.2 & 57.7 \\
\hline 6 & $\left(\mathrm{CF}_{3}\right)_{3} \mathrm{COH}$ & 5.2 & 87 & 94 & 61500 & 1.78 & 13.0 & 49.4 & 37.6 & 62.3 \\
\hline
\end{tabular}

${ }^{a}[\mathrm{VAc}]_{0}=2.2 \mathrm{M}(20 \mathrm{vol} \%),[\mathrm{AIBN}]_{0}=0.15 \mathrm{M}$, time; $1 \mathrm{~h}$ (run 1) or $24 \mathrm{~h}$ (runs 2-6).

${ }^{b}$ Ref. 14.

${ }^{c}$ Determined by ${ }^{1} \mathrm{H}$ NMR in $\mathrm{CDCl}_{3}$.

${ }^{d} \mathrm{Et}_{2} \mathrm{O}$-insoluble part.

${ }^{e}$ Determined by GPC of original polymers using standard polystyrenes.

${ }^{f}$ Determined by ${ }^{1} \mathrm{H}$ NMR of PVA in DMSO- $d_{6}$.

${ }^{g}$ Calculated based on triad tacticity $(r=r r+m m / 2)$.

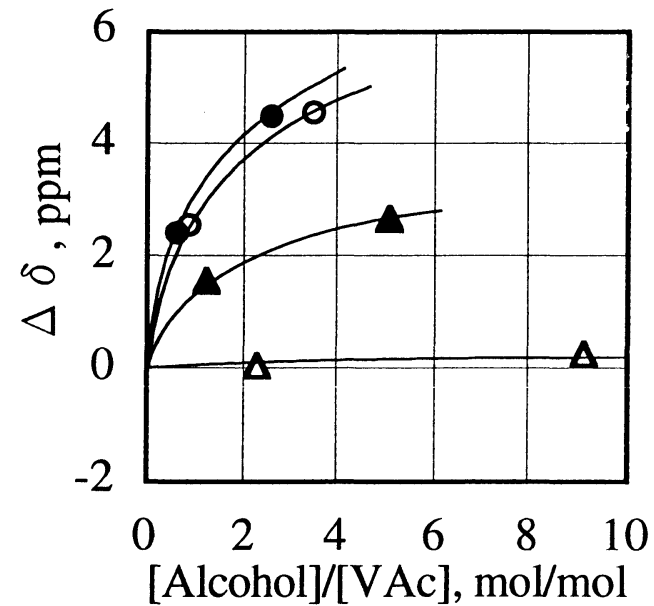

Fig. 1. Change of the ${ }^{13} \mathrm{C}$ NMR carbonyl carbon chemical shifts of VAc in various alcohols: $\mathrm{CH}_{3} \mathrm{OH}(\triangle), \mathrm{CF}_{3} \mathrm{CH}_{2} \mathrm{OH}(\boldsymbol{\Delta})$, $\left(\mathrm{CF}_{3}\right)_{2} \mathrm{CHOH}(\mathrm{O})$, and $\left(\mathrm{CF}_{3}\right)_{3} \mathrm{COH}(\mathbf{O})$ (The chemical shift of VAc in neat solution was taken as $\triangle=0$ ).

was especially effective in enhancing the syndiotactic specificity and a polymer with a dyad $r$ of over $62 \%$ was obtained under the reaction conditions of run 6 . It is clearly seen that a solvent with a lower $\mathrm{pKa} \mathrm{a}^{14)}$ (higher acidity) gives a polymer with a higher syndiotacticity, suggesting that a stronger solvent-acetyl group interaction may lead to better stereocontrol. Fig. 1 shows change of the ${ }^{13} \mathrm{C}$ NMR carbonyl carbon chemical shifts of VAc in various alcohols to that of the neat VAc. The ${ }^{13} \mathrm{C}$ NMR resonances remarkably shift downfield as the $\mathrm{pKa}$ of an alcohol decreases and as the ratio of an alcohol to VAc increases. These results strongly support the existence of the hydrogen-bonding between the alcohol molecules and VAc.
Table II. Relationship between $M / \rho$ and syndiotacticity ${ }^{a}$

\begin{tabular}{|c|c|c|c|}
\hline \multirow{2}{*}{ Run } & \multirow{2}{*}{ Solvent } & \multirow{2}{*}{$\frac{M / \rho}{\mathrm{mL} / \mathrm{mol}}$} & \multirow{2}{*}{$\frac{\text { Dyad syndiotacticity }^{b}}{r / \%}$} \\
\hline & & & \\
\hline 1 & None & - & 52.9 \\
\hline 2 & $\mathrm{CH}_{3} \mathrm{OH}$ & 41 & 53.2 \\
\hline 3 & $\mathrm{CF}_{3} \mathrm{CH}_{2} \mathrm{OH}$ & 73 & 55.2 \\
\hline 4 & $\left(\mathrm{CF}_{3}\right)_{2} \mathrm{C}\left(\mathrm{CH}_{3}\right) \mathrm{OH}$ & 123 & 57.1 \\
\hline 5 & $\left(\mathrm{CF}_{3}\right)_{2} \mathrm{CHOH}$ & 105 & 57.7 \\
\hline 6 & $\left(\mathrm{CF}_{3}\right)_{3} \mathrm{COH}$ & 139 & 62.3 \\
\hline
\end{tabular}

${ }^{a}$ Polymerization conditions are indicated in Table I.

${ }^{b}$ Calculated based on triad tacticity $(r=r r+m m / 2)$.

The hydrogen-bond interaction must be stronger in an alcohol with a lower $\mathrm{pK}$ a, like $\left(\mathrm{CF}_{3}\right)_{3} \mathrm{COH}$.

Another solvent property which may affect the stereochemistry of polymerization seems to be bulkiness of the solvents. Bulkiness of a solvent can be evaluated as the molecular volume $(\mathrm{mL} / \mathrm{mol})$ which is defined as the ratio of molecular weight $(M)$ to density $(\rho)$. Table II summarizes the values of $M / \rho$ of the solvents and the syndiotacticity of the polymers obtained in the solvents. The data indicate the tendency that a solvent with a higher $M / \rho$ leads to a higher syndiotacticity. These results suggest that the side chains of the monomer and polymer increase the 'apparent bulkiness' through hydrogen-bonding with the bulky solvent molecules and this change in the bulkiness may enhance the syndiotactic specificity of the polymerization by steric repulsion.

Temperature effects. Since $\left(\mathrm{CF}_{3}\right)_{3} \mathrm{COH}$ exhibited the largest effect in enhancing the syndiotactic specificity of the polymerization, the polymerization in 
Table III. Radical polymerization of VAc in $\left(\mathrm{CF}_{3}\right)_{3} \mathrm{COH}$ at various temperatures ${ }^{a}$

\begin{tabular}{|c|c|c|c|c|c|c|c|c|c|c|}
\hline \multirow{2}{*}{ Run } & \multirow{2}{*}{$\frac{\text { Temp. }}{{ }^{\circ} \mathrm{C}}$} & \multirow{2}{*}{$\frac{\text { Time }}{\mathrm{h}}$} & \multirow{2}{*}{$\frac{\text { Conv. }^{b}}{\%}$} & \multirow{2}{*}{$\frac{\text { Yield }^{c}}{\%}$} & \multirow{2}{*}{$M n^{d}$} & \multirow{2}{*}{$M w / M n^{d}$} & \multicolumn{3}{|c|}{ Triad tacticity $^{e}$} & \multirow{2}{*}{$\begin{array}{c}\text { Dyad syndiotacticity } \\
r / \%\end{array}$} \\
\hline & & & & & & & $m m$ & $m r$ & $r r$ & \\
\hline 1 & 40 & 3 & 65 & 68 & 142600 & 1.59 & 15.3 & 50.3 & 34.3 & 59.5 \\
\hline 2 & 20 & 24 & 87 & 94 & 61500 & 1.78 & 13.0 & 49.4 & 37.6 & 62.3 \\
\hline 3 & 0 & 48 & 55 & 43 & 115300 & 1.79 & 11.5 & 49.0 & 39.4 & 64.0 \\
\hline 4 & -78 & 144 & 58 & 51 & 74900 & 1.92 & 5.9 & 44.2 & 49.9 & 72.0 \\
\hline
\end{tabular}

${ }^{a}[\mathrm{VAc}]_{0}=2.2 \mathrm{M}$. Polymerization at $0 \sim 40^{\circ} \mathrm{C}$ was carried out with AIBN $(0.15 \mathrm{M})$. Reaction at 0 and $20^{\circ} \mathrm{C}$ was initiated by UV irradiation. Polymerization at $-78^{\circ} \mathrm{C}$ was carried out with $n \mathrm{Bu}_{3} \mathrm{~B}(0.20 \mathrm{M})$ in the presence of a small amount of air.

${ }^{b}$ Determined by ${ }^{1} \mathrm{H}$ NMR in $\mathrm{CDCl}_{3}$.

${ }^{c} \mathrm{Et}_{2} \mathrm{O}$-insoluble part.

${ }^{d}$ Determined by GPC of original polymers using standard polystyrenes.

${ }^{e}$ Determined by ${ }^{1} \mathrm{H}$ or ${ }^{13} \mathrm{C}$ NMR of PVA in DMSO- $d_{6}$.

${ }^{f}$ Calculated based on triad tacticity $(r=r r+m m / 2)$.

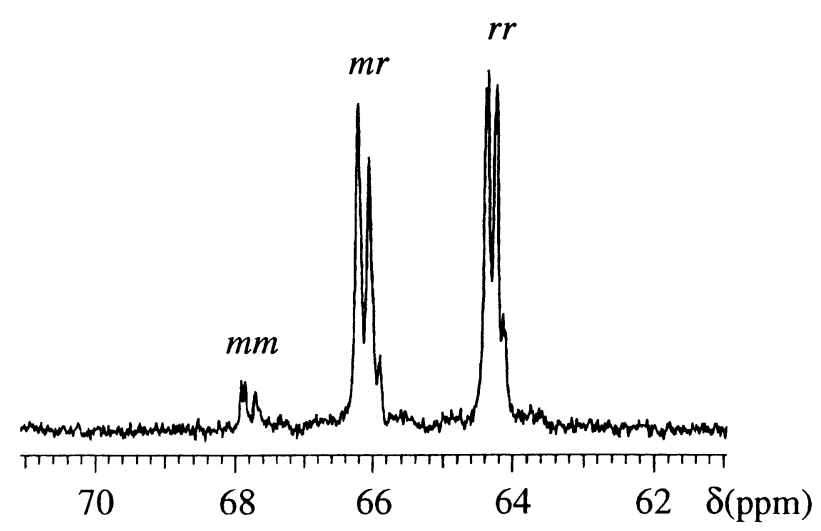

Fig. 2. $125 \mathrm{MHz}{ }^{13} \mathrm{C}$ NMR spectrum (methine region) of PVA obtained in run 4 in Table III $\left(\mathrm{DMSO}-d_{6}, 100^{\circ} \mathrm{C}\right)$.

$\left(\mathrm{CF}_{3}\right)_{3} \mathrm{COH}$ was carried out at various temperatures (Table III). These results indicate that syndiotactic specificity increases at lower temperatures. The polymerization at $-78^{\circ} \mathrm{C}$ (run 4) gave a polymer with a dyad syndiotacticity of $72 \%$, which is the highest value among the free-radically obtained poly(vinyl esters). Fig. 2 shows the ${ }^{13} \mathrm{C}$ NMR spectrum (methine region) of the PVA derived from this polymer.

Melting points of PVA. Stereoregular PVA is considered to have superior thermal and mechanical properties. Melting point (Tm) may be a criterion for the heat-resistance property of PVA. Recently, it was reported that the PVA derived from poly(VPi) obtained in $n$-hexane had a dyad syndiotacticity of $69 \%$ and a Tm of $258^{\circ} \mathrm{C}$. ${ }^{6)}$ Fig. 3 shows the relationship between syndiotacticity and Tm of PVAs obtained through the polymerization of VAc in $\left(\mathrm{CF}_{3}\right)_{3} \mathrm{COH}$ in the present study together with those obtained from the poly(VPi) ${ }^{6), 15), 16)}$ With an

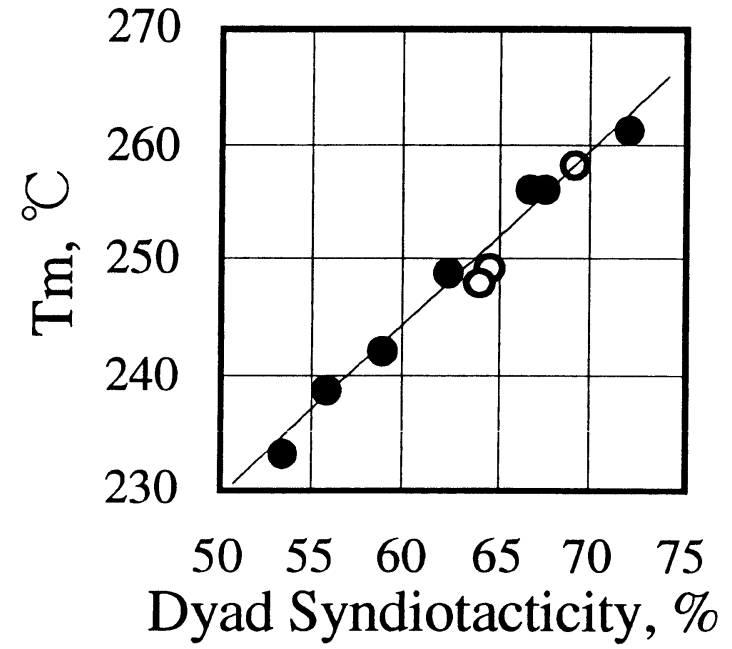

Fig. 3. Relationship between the syndiotacticity and the melting point of PVA derived from poly(VAc) $(O)$ and poly $(\mathrm{VPi})(\mathrm{O})$

increase in syndiotacticity, Tm increases and the PVA with $r=72 \%$ shows a $\mathrm{Tm}$ of $261^{\circ} \mathrm{C}$. This value is higher than that of the PVA with $r=69 \%$ derived from the poly(VPi). ${ }^{6}$ This stereoregular PVA is also expected to be superior in other properties such as mechanical strength.

In conclusion, we obtained highly syndiotactic poly(VAc) through the polymerization in $\left(\mathrm{CF}_{3}\right)_{3} \mathrm{COH}$ at low temperature. The derived PVA showed a high melting point. This syndiotactic specificity may be caused by the steric repulsion between the side groups bound by the fluoroalcohol.

Acknowledgments. This work was supported by NEDO for the project on Technology for Novel HighFunctional Materials in Industrial Science and Technology Frontier Program, AIST. 


\section{References}

1) For reviews: (a) Finch, C. A. (ed.) (1992) Polyvinyl Alcohol Developments, Wiley, Chichester; (b) PVA no Sekai (The World of PVA), Kobunshi Kankokai, Kyoto (1992); (c) Fujii, K. (1971) J. Polym. Sci., Macromol. Rev. 5, 431-540.

2) Matsuzawa, S., Yamaura, K., Noguchi, H., and Hayashi, H. (1973) Makromol. Chem. 165, 217-222.

3) Matsuzawa, S., Yamaura, K., and Noguchi, H. (1973) Makromol. Chem. 168, 27-32.

4) Nozakura, S., Sumi, M., Uoi, M., Okamoto, T., and Murahashi, S. (1973) J. Polym. Sci., Polym. Chem. ed. 11, 279-288.

5) Fukae, R., Yamamoto, T., Fujita, Y., Kawatsuki, N., Sangen, O., and Kamachi, M. (1995) Polym. J. 27, 1257-1259.

6) Fukae, R., Yamamoto, T., Fujita, Y., Kawatsuki, N., Sangen, O., and Kamachi, M. (1997) Polym. J. 29, 293-295.

7) Nakano, T., Makita, K., and Okamoto, Y. Polym. J. (submitted).
8) Yamada, K., Nakano, T., and Okamoto, Y. Polym. J. (submitted).

9) Yamamoto, T., Yamamoto, T., Minamizawa, T., and Hirota, M. (1979) Kobunshi Ronbunshu 36, 557-560 (CA 91, 158200).

10) Kador, U., and Mehnert, P. (1971) Makromol. Chem. 144, 29-35.

11) Imai, K., Shiomi, T., Oda, N., and Otsuka, H. (1986) J. Polym. Sci., Part A 24, 3225-3231.

12) Clarke, J. T., Howard, R. O., and Stockmayer, W. H. (1961) Makromol. Chem. 44/46, 427-447.

13) Kamachi, M. (1980) Adv. Polym. Sci. 38, 55-87.

14) Filler, R., and Schure, R. M. (1967) J. Org. Chem. 32, 1217-1219.

15) Fukae, R., Yamamoto, T., Sangen, O., Saso, T., Kato, T., and Kamachi, M. (1990) Polym. J. 22, 636-637.

16) Lyoo, W. S., and Ha, W. S. (1997) J. Polym. Sci., Part A 35, $55-67$. 